all recorded cases illustrating the remarkable effects of digitalis are cases of auricular fibrillation. Hearts with the normal rhythm are seldom so sensitive to the digitalis, and in them there is not the same tendency to slowing of the rate.

While in all successful systems of treatment rest is always prescribed, its good results are not always recognised, because at the same time some special agent is employed, such as a drug, a bath, or an exercise, and the good results are attributed to the special agent. It is for this reason that the therapy of heart affections is loaded by such an array of therapeutical measures, the vast majority of which have little or no effect on the heart. Many of these agents are not only given when rest has also been prescribed, but they are given when there is no heart failure, and only because the physician has detected some anomalous symptom. It is a matter of everyday experience to find individuals with a murmur or an irregularity, who for years have been subjected to treatment and made to visit health resorts for a condition which neither indicates heart failure in the present nor its likelihood in the future. The fact that heart failure did not arise has probably been attributed to the precautionary measures. From this comes the belief in the efficacy of many of the drugs and methods in use to-day. When many of these vaunted remedies are carefully investigated their uselessness becomes evident. Take, for instance, the present-day belief in the effect of strychnia on the heart, a belief held not only by a great many physicians but which exercises an almost superstitious regard in the mind of many of our surgical brethren, in whom the faith is so deeply rooted that they will not undertake an operation without the preliminary ceremonial rite of a hypodermic injection of strychnia. I have sought in vain for the slightest evidence of the effect of medicinal doses of strychnia upon the heart, and have searched the literature on the subject and have not found one single reliable instance demonstrating the effects of medicinal doses. Pharmacologists have repeatedly examined with the minutest care the effects of medicinal doses of strychnia upon the heart in experiment, and have failed to obtain a result of any kind. So it is with a great many other drugs and methods, with the unfortunate result that the effects of drugs that are really of service are never properly appreciated.

We might not care so much for these erroneous beliefs were it not that they blind the profession to the great want of suitable agents in treating real and serious affections of the heart. - There are many conditions in which rest alone fails to benefit the heart, as when the heart is invaded by a toxin, or rendered irritable from some lesion in the heart itself, or when the ventricle in heart-block contracts so seldom as to endanger life. For these and many other conditions we are absolutely without any means of meeting the jmpending and actual danger, and yet we are kept in ignorance of this fact, because writers pour forth a stream of remedies for any and every kind of heart trouble. Were we more alive to our own limitations, we should be more industrious in the search for real and valuable remedies.

\section{THE INDICATIONS FOR, AND TECHNIQUE OF, CASAREAN SECTION}

AND ITS ALTERNATIVES, IN WOMEN WITH CONTRACTED PELVES, WHO HAVE BEEN LONG IN LABOUR AND EXPOSED TO SEPTIC IN FECTION. ${ }^{1}$

BY AMAND ROUTH, M.D. LoND., F.R.C.P. LoND., OBETETRIC PHYSICIAN AND LECTURER ON MIDWIFERY, CHARING-CROSS HOSPITAL, ETC.

AFTER my visit to the Congress at St. Pelersburg I realise fully the difficulty of this question. Let me first draw attention to Table I., which shows the enormous difference between the mortality of the "clean" and the "suspected" cases.

It will be seen that the cases in Groups A and B had a death-rate of only 29 per cent., whereas in Groups $C$ and $D$ the mortality was $17 \cdot 3$ per cent. In Group $D$ the death-rate was as high as $34 \cdot 3$ per cent. ( 22 deaths in 64 cases). To

Being an address introductory to a discussion at the Obstetrical and Gynæculogical Section of the Royal Society of Medicine, Feb. 2nd, 1911.
TABLE I.-Showing the Mortality of Casavean Operations for Contracted Pelvis where Details are given as to Possible Infectivity (1891 to 1910).*

\begin{tabular}{|c|c|c|c|c|}
\hline - & Condition. & Cases. & $\begin{array}{l}\text { Maternal } \\
\text { deaths. }\end{array}$ & $\begin{array}{l}\text { Percentage } \\
\text { mortality. }\end{array}$ \\
\hline $\mathbf{A}$ & "Not in labour" $\quad \ldots \quad \ldots \quad \ldots \quad \ldots$ & 245 ? & 9 ). & 3.62 \\
\hline $\mathbf{B} \dagger$ & In labour, membranes intact ... & $224\} 469$ & $5 \longdiv { 1 4 }$ & $2 \cdot 2^{2 \cdot 9}$ \\
\hline $\mathbf{C}$ & In labour, membranes ruptured & 166 & $18)$ & $10 \cdot 87$ \\
\hline D & $\begin{array}{ccc}\text { Frequent examinations } & \text { or } \\
\text { attempts at delivery } & \ldots & \ldots\end{array}$ & & & $34 \cdot 3\}^{1}$ \\
\hline
\end{tabular}
and Gynacology of British Empire, January, 1911.

$\dagger \mathbf{B}$, or " onset of labour," or "in labour but in hospital some days."

lessen this mortality Porro's Cæsarean hysterectomy, symphysiotomy, pubiotomy, and more recently (1907) extraperitoneal Cæsarean section and Sellheim's utero-abdominal fistula have been adopted for these "suspect cases."

The disadvantages of the extra-peritoneal operation in septic cases may be enumerated as follows. 1. The uterus, with its large placental site, its decidual surface, and its incised wall, is retained as a channel for infection. 2. The peritoneum is bruised, and when stripped off, necessarily loses to a large extent its blood-supply, and is liable to become less resistant to seplic processes. 3 . The under surface of the peritoneum, thus to some extent devitalised and injured, is during the operation constantly in contact with any septic germs present in utero. As a result a large percentage of the fatal cases die from peritonitis. 4. A large area of connective tissue is opened up and exposed to infection.

Sellheim's ntero-abdominal fistula operation may help to save lives in septic cases where primary union of the uterine wound fails, as in a case of my own (1045) in 1909, where a utero-abdominal fistula accidentally formed. Attempts had been previously made to deliver by forceps, but by such experienced accoucheurs that I hoped infection was absent. When the child was extracted by Cosarean section I found the head abraded, and in a few days septic sloughs and abscesses appeared both on the child's head and over the abdominal wound, and a utero-abdominal fistula developed. Three months afterwards appendicitis supervened, and at the operation for that condition by Mr. Stanley Boyd the fistula was closed. This patient emigrated to Canada a hundred miles away from a town and writes that she is again pregnant.

There is no consensus of opinion abroad, every alternative to classical Cæsarean section being recommended by their votaries, but many are coming round to the British view that septic cases should not be treated by extra-peritoneal Cæsarean section or by pelviotomy, but by either embryotomy or some form of hysterectomy-the original Porro operation being usually preferred abroad.

There is no clinical method by which we can in earty cases in the absence of pyrexia, offensive discharge, \&c., diagnose with assurance whether a woman is already infected or not. It is often pure guess-work. I wish, therefore, to discuss the subject from the bacteriological point of view, for much advantage will be gained if treatment of these septic cases can be placed upon a scientific basis, and if the operation can be safely varied according to the type of the germs found to be present, as was suggested by Bumm, Veit, and others at the recent Congress. These germs may be divided into pathogenic and putrefactive. Pathogenic germs, such as streptococci, not only cause local inflammatory disturbances, but unlike true putrefactive germs multiply in the blood. If they infect the uterine wound in Cæsarean section they will prevent primary union, and will then infect the peritoneum. Putrefactive germs if present in large numbers will probably also prevent primary healing of the wound, for Arnold Lea states that cultures of anaerobic putrefactive organisms injected hypodermically into animals produce localised suppuration often followed by extensive gangrene.

The most serious cases of puerperal infection are due to the presence of streptococci, ${ }^{2}$ or streptococci and bacillus coli combined. Pneumococci, staphylococcus pyogenes aureus, and gonococci are also dangerous. Staphylococcus pyogenes albus and bacillus coli are less virulent germs. 
Foulerton and Bonney failed to find anaerobic germs, which would include ordinary saprophytic organisms, in 53 out of 54 cases of puerperal fever. On the other hand, Krönig found them in 18 per cent. of 179 cases, and WhitridgeWilliams in 15 per cent. of 151 cases. The actual danger from the presence of putrefactive germs is not yet exactly known. At the Congress Bumm said : "The measure of the danger depends npon the kind of infection. The decomposition of the liquor amnii by ascending putrefactive germs is less dangerous than the presence of streptococci, the ample appearance of which in the liquor amnii leaves no doubt as to the existence of a virulent infection."

Bumm says that the presence of putrefactive germs prevents the primary union of the muscle wound of the uterus and causes fatal peritonitis, and he adds: "If the amnion has been ruptured for some time and there is even only a slight elevation of temperature classic Cæsarean section is fatal." He continues: "In performing suprasymphysary Cæsarean section, if one succeeds in finishing the obstetric act extraperitoneally, one has the possibility, by ample draining of the cellular tissue wounds, of avoiding the danger of a general infection in all those cases where one has to deal with a simple putrefactive decomposition of the liquor amnii. If, however, the uterus at the time of the operation already contains streptococci, a fatal result may follow by progressive phlegmon of the pelvis, septic thrombophlebitis, or by the migration of the germs through the thin layer of peritoneum covering the utero-vesical excavation."

In reply to a letter from me to Professor Bumm, asking for further information, Dr. Edward Martin replied in English on Nov. 9th last :-

On behalf of Professor Bumm I answer the question of your letter. In every case of contracted pelvis without fever we have to perform the delivery by suprapubic section. When the waters are passing away we make a bacteriological examination by microscope. In all cases of bacteria of any kind we object to the section and make the perforation of the child. In all suspicious cases, when the patient has been examined outside of the Klinik at several times, or when she has elevated temperature, when germs are not found we make it a rule to perform suprapubic section only, but in such cases we make use of drainage. When bacteria are found in fever cases we perforate the child.

Veit says the danger of Cæsarean section consists in the infection by virulent germs or in the penetration of germs of putrefaction from the genital canal into the abdominal cavity with the blood or liquor amnii. With virulent germs he considers all' varieties of Cæasarean section inadnissible. The penetration of germs of putrefaction into the abdominal cavity, he considers, can be prevented by various methods of extraperitoneal Cresarean section, and also to a large extent by eventration of the uterus before incision in ordinary Cæsarean section with careful packing round the uterus, and he prefers in such cases Fritsch's transverse fundal incision.

When a parturient woman is said " to have been exposed to infection," as we are now discussing, her danger must largely depend upon the variety and virulence of the infecting organism, as well as by the length of time which has elapsed since the infection, and the presence of abrasions as absorbent areas. If the membranes are ruptured and the amniotic cavity has been infected the micro-organisms will rapidly multiply there, for the liquor amnii is a suitable culture medium.

With our present imperfect knowledge of the interaction between different kinds of bacteria and their power of increasing or reducing each other's activity and virulence it is evident that in the presence of both virulent and putrefactive organisms one would have 'to treat the case from the point of view of the more virulent germs. It is not always necessary to obtain swabs from the cavity of the amnion, for if a case has been frequently examined, or forceps have been used, and potentially virulent germs are found in the cervix or upper vagina, it is manifest that they must have been carried up into the uterus and that the liquor amnii is infected. Apart from the introduction of an examining finger or instrument into the uterus, Arnold Lea says that the cervical plug of mucus is usually able, owing to the presence of phagocytes, to prevent vaginal streptococci, \&c., from infecting the amniotic cavity.

It is evident that if the technique of these Casarean operations is to be varied according to the presence, absence, or variety of the infecting germ we must have a report presented to us within an hour or so of the "suspect case" being admitted to hospital. We cannot wait for cultural examination.

Probably the greatest difficulty in the bacteriological investigation is to be able to recognise the dividing line between saprophytic and pathogenic germs, for, as Arnold Lea says, the same organism may under different conditions entirely change its character. Thus, the streptococcus pyogenes may exist as a pure saprophyte in the genital tract, whilst some anaerobic putrefactive bacteria may become highly infective. It is also apparently true that if a puerperal uterus be invaded by streptococci, acting at first solely as pure saprophytes and temporarily only causing toxæmia (sapræmia), conditions may arise (? diminished resistance in the patient) in which the streptococci may become infective and true septicæmia result. If streptococci are found we must therefore assume they are virulent and act accordingly. There is at present no rapid method by which we can differentiate between the 38 brands of streptococci said to exist. Subject to these limitations, however, I believe that sufficiently reliable reports from the microscopic examination of these swabs can be obtained.

Mr. A. N. Leathem, bacteriologist at Charing Cross Hospital, states "that films could be made and stained from uterine swabbings, and if the organisms were present in considerable numbers a reliable report as to the presence of streptococci, staphylococci, or pneumococci could be given within half an hour. If bacilli were present it would be more difficult to decide as to the presence of $B$. coli, although in some cases it would probably be possible to say that the bacilli present in the films were all saprophytic." I also put the case to Sir Almroth Wright, who writes: "It seems to me that in such a case as you refer to it would be well worth while making a bacteriological examination, for it might be possible, in cases where there was a considerable amount of infection, to detect and identify the microbes by mere microscopic examination. In the majority of cases it would, of course, be impossible to detect or identify the microbes without awaiting the results of cultures."

The next point was to find out by a series of tests whether a report obtained from the examination of films was confirmed by a further examination of cultures from these same swabbings-whether, in fact, the report from the film examination was sufficiently reliable to be aoted upon. For this purpose Mr. Leathem has reported upon the examination of swabbings, first of stained films, and subse. quently of the cultures from the same swabs. The first five of these are given in the appendix to the paper. As my object was mainly to discover whether the film results were confirmed by the culture tests I have, in the absence of Crsarean section cases, taken swabbings from the cervix and uterine body of other cases. As a result of such investigations (see Appendix) I believe that these rapidly obtained film results when reported on by those who are experts are usually sufficiently reliable to justify us in adopting a particular type of operation according to the variety of microorganisms found present, though apparently such reports would tend to make one operate radically in some cases where cultural examination would subsequently show it had not been really necessary. On the other hand, both $D r$. Banister and Dr. R. D. Maxwell, who have also kindly made tests, tell me that in a few cases they failed to find streptococci in the films, but cultures showed their presence. This, if not very exceptional, would prove a seriously weak point. Presumably the germs were few and stained badly. I hope that in the future greater reliability will be able to be placed upon these film reports-perhaps by more perfect methods of differential staining.

\section{Indioations for Treatment.}

The cases we are considering are "suspect cases" and may roughly be divided into five classes :-

1. Cases which have been exposed to infeotinn, but where the membranes are not ruptured. - If germs had been carried into the vagina during previous examinations they could almost certainly be destroyed or rendered harmless by copious vaginal antiseptic douches.

2. Second type of case. In labour some hours, membranes ruptured, vaginal examination made, no feverishness, no offunsive disoharge. The liquor amnii is found to be sterile.Here a classical Casarean section could be safely done, though some would prefer to eventrate the uterus before incision as the woman has been previously examined. 
3. Third type of oase. In labour some hours, membranes quptured, examinations made or attempts at delivery, some offensiveness of discharge, possibly some feverishness.-We will assume that saprophytic organisms are found in the liquor amnii but no pathogenic organisms. Primary union of the uterine wound might fail in these cases, and unless a uteroabdominal fistula formed fatal peritonitis would then follow. This group may perhaps be represented by Cases 811 and 841 , both of which women had been long in labour and were treated by Cresarean section and died from sepsis. In each case when the amniotic cavity was opened it was found to contain air which was very foetid. Unfortunately no bacteriological test of the liquor amnii appears to have been made in these cases. Both children were alive at birth, but one, upon whom forceps had been used, died on the second day.

Extraperitoneal Cresarean section and all forms of pelviotomy being, in my opinion, better avoided for septic cases, and classical Cæasarean section being very fatal (Table I.), there remains only craniotomy or some variety of Cæsarean hysterectomy.

I wish here to speak of an alternative prophylactci measure-intra-amniotic irrigation-adopted by Dr. Maxwell of Queen Charlotte's Hospital in doubtful cases of infection where the membranes are ruptured. A soft pewter or other pliable tube is passed up per vaginam to the fandus uteri, and the amniotic cavity and incidentally the fotal skin are freely irrigated with normal saline solution at $100^{\circ} \mathrm{F}$. Possibly a saturated boric solution would be more useful if micro-organisms were present. The method is, of course, available in all degrees of pelvic contraction. It might also be usefully employed before craniotomy to dilute any suspected infection in the amniotic cavity and so reduce the risk of infection of the tissues if they were abraded during the operation. Whether it is possible to so thoroughly irrigate the amniotic cavity that all putrefactive organisms can be washed away or rendered harmless is only a question which can be settled by experience. If most of the liquor amnii had drained away, and especially if the uterine muscle were contracted down on the child, such irrigation could only be very partial. The diffeulty, too, of dislodging germs from fotal apertures and irregularities, or those luxuriating in a vernix caseosa is evident. Still it is an additional method at our disposal and may prove of great value. In any case it must dilute the poison and, so to speak, "lessen the dose." If Maxwell's method does not prove reliable, and there is no constitutional or bacteriological evidence of infection by potentially virulent pathogenic organisms, it is probable that craniotomy with intra-uterine irrigation would be the best treatment, for at this stage the infection is recent, the germs therefore few, and the placental site and decidua are protected by the membranes from infection. If, on the other hand, Maxwell's method or some modification of it should prove serviceable, it would largely prevent craniotomy with living children in those "suspect cases," and would enable Cæsarean section to be done safely in cases where it could be shown bacteriologically that there was no virulent infection present.

4. Groups 4 and 5. In labour many hours, membranes ruptured, frequent examinations made, or attempts at delivery. Pathogenuogerms of potential virulenoe found. Constitutional evidenoe of infection.-Here it is probably correct to assume that Maxwell's method would be useless, and that such rapidly multiplying and invading pathogenic germs as streptococci, \&c., could not be successfally dealt with, even in a case very recently infected, by any irrigating fluid which was not so powerfully antiseptic as to cause serious injury to the foetus.

Craniotomy would no doubt be preferable to such futile attempts to destroy the infecting germs, but it must be remembered that abrasions of the cervix and vagina during the extraction of the mutilated foetus after craniotomy are almost inevitable, and if virulent germs such as streptococci are present the maternal tissues might become infected, and septicæmia would occur. Probably, therefore, if such germs were proved to be present a radical operation would be preferred. In other words, where there are constitutional evidences of sepsis, and potentially virulent germs are found, some form of Cæsarean hysterectomy is indicated. A few words regarding the relative advantages of the two varieties of subtotal hysterectomy and abdominal panhysterectomy in virulent infection are here necessary.
A. First as regards supravaginal hystereotomy woth intraperitoneal treatment of the stump.-Here let me draw your attention to Table II., taken from my recent report upon Cæasarean section.

TABLE II.-Showing Mothod of Treatment* of the 230 Cases in Table I. (Groups $C$ and $D$ ) which may have been exposed to Infeotion (1891 to 1910). "Suspect Cases."

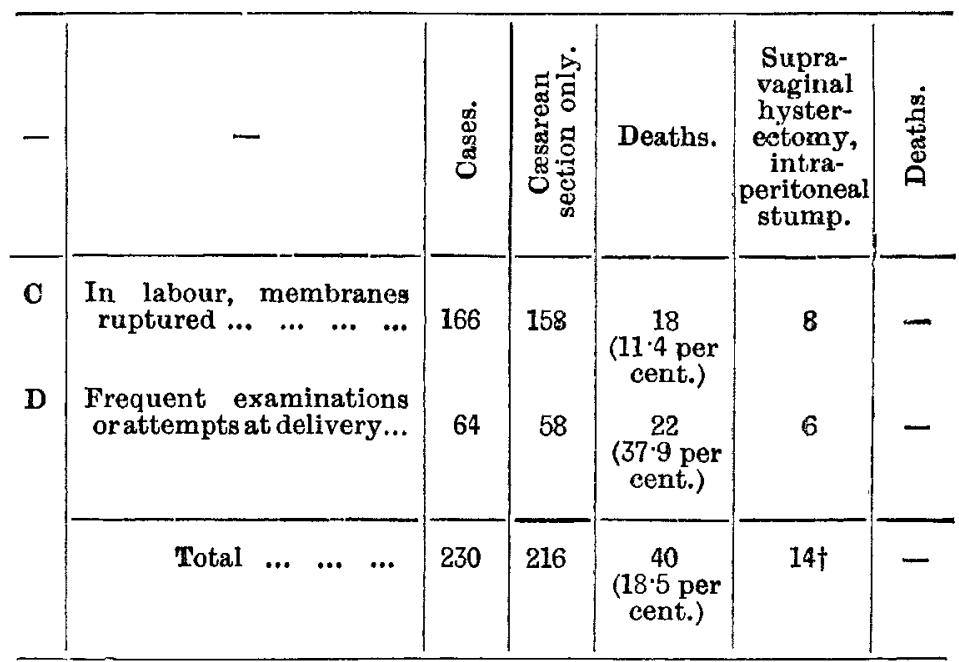

* The early cases (1867 to 1890), where supravaginal hysterectomy with extraperitoneal treatment of the stump was the technique adopted, cannot be tabulated owing to want of sufficient details regarding the "rupture of the membranes.

$\dagger$ Cases 336, 358, 370, 400,404, 405, 432, 494, 568, 713, 736, 751, 843, and

This table divides the 230 "suspect cases" in Groups C and $\mathbf{D}$ of Table $I$. into two other groups according to their treatment by Casarean section only, or by supravaginal hysterectomy with intraperitoneal treatment of the stump. It will be seen that in Group $\mathrm{C}$, where the membranes were already ruptured, the mortality of Crsarean section alone was 11.4 per cent., and in Group D, where attempts at delivery or frequent examination had been made, the mortality of Cæsarean section alone was 37.9 per cent. In these two groups $\mathrm{C}$ and $\mathrm{D} 14$ cases were treated by supravaginal hysterectomy with intraperitoneal treatment of the stump, and of these all the mothers survived and 11 of the children. Ten of these 14 " suspect" or infected cases which recovered were operated upon in Glasgow by Cameron, Jardine, and Munro Kerr, the others by Berkeley, Brewis, and Purslow. It is probable that several of these cases were infected by pathogenic organisms, and if so it makes the results of the radical operations more striking, especially when, as I show in my report read at St. Petersburg, the mortality in 39 other cases of contracted pelvis treated by this radical operation as a routine method there were seven deaths $=17 \cdot 9$ per cent.

If the cervix is left in these infected cases it should be reodered as harmless as possible, either by applying a strong antiseptic application to the cervical canal from above, or a strip of gauze may be passed downwards into the vagina through the cervical canal. The covering of the stump with peritoneum should be very accurately and carefully executed.

B. Supravaginal hystereotomy (Porro's), with eatraperitoneal treatment of the stump. - This method more effectively shuts off the peritoneal cavity from the infected cervix and vagina than any other variety of hysterectomy, in addition to which no ligatures are left in the peritoneal cavity. This variety of subtotal hysterectomy is strongly advised by Spencer and others in such septic cases as inoperable cancer of the cervix complicating labour. There were 28 cases of contracted pelvis in my collection treated by Cæsarean hysterectomy with extra-peritoneal treatment of the stump with 4 deaths, a mortality of $14 \cdot 2$ per cent., which compares favourably with the 132 per cent. mortality of 53 cases dealt with by intraperitoneal treatment of the stump. When it is further remembered that the cases treated in this way were operated upon mainly before 1895, when many were septic before coming under notice, the comparative safety of the operation with extra-peritoneal treatment of the stump is highly suggestive. This variety of subtotal hysterectomy is recommended in these cases by Brandt, Schauta, Pestalozza,

3 Journal of Obstetrics and Gynæcology of the British Empire, January, 1911. 
and others abroad, and seems especially indicated for gonococcal infection.

O. Abdominal panhystereotomy. - This operation is theoretically the ideal one for cases infected with potentially virulent pathogenic organisms, as it involves removal of the infected glandular cervix. There are, however, risks in the operation as now done.

1. One is the difficulty of performing the preliminary operation of Crsarean section without infecting the peritoneal cavity during its performance, for panhysterectomy without a preliminary Cæsarean section cannot be performed so rapidly that the child would have a fair chance of survival if it were extracted after the removal of the uterus, even by Doyen's method, where the uterine vessels are divided at a late stage. To prevent infection of the peritoneum during the delivery of the child the uterus must first be eventrated and the abdominal incision temporarily closed, and the peritoneal cavity shut off by packing round the uterine neck. A fundal incision should then be made into the uterus, the child extracted, and the uterine wound accurately closed again. Panhysterectomy can then be performed, Wertheim's clamps being used to prevent infection from the vagina; or, to prevent the shortening of the vagina which this operation involves, the uterus can be removed by Doyen's method, the cervix having been previously closed by ligatures as advised by Spencer.

2. The risk of infection of the peritoneum from the septic vagina after the uterus is removed is more difficult to avoid. If Spencer's method of ligation of the cervix were adopted as a preliminary to the operation the vagina could be sterilised at the same time, perhaps by swabbing with tinctura iodi, for effective sterilisation after the bysterectomy would be difficult.

The treatment of the divided end of the vagina is important. Personally, I think its cut edges should be inverted and sutured, a small opening being left in the centre of the canal for a gauze drain.

The treatment of the peritoneum on the pelvic floor is also important. Should it be stitched across transversely by continuous Lembert sutures, or should it be closed by Spencer's method of purse-string suture, or should it be left open to drain per vaginam, and if so should a gauze drain be used?

The success of panhysterectomy in these cases will depend upon a technique perfected in these small details.

In conclusion, I would say that I am not without hope that a rapid bacteriological examination of films prepared from the liquor amnii or cervical contents in "suspect" cases when the membranes are ruptured will enable the treatment of these cases to be put on a more scientific basis. If so classical Cæsarean section would be performed with perfect security if the fluid were sterile; Cæsarean section, preceded by some variety or some evolution of Maxwell's intraamniotic irrigation and by eventration of the uterus, might be considered safe if non-pathogenic germs were found; and a radical hysterectomy would be considered desirable if pathugenic micro-organisms were discovered. It is possible that such a scientific basis may do away with the need for craniotomy with living children in well-organised obstetric clinics, but craniotomy would still be required in general practice where prompt bacteriological investigation and special technical experience might not be forthcoming.

APPENDIX

Iests made by Mr. Leathem to ascertain whether Examination of Films from Cervix Uteri, fo., was sufficiently reliable to bo aoted upon.

\begin{tabular}{|c|c|c|c|c|c|}
\hline 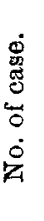 & Variety of case. & $\begin{array}{l}\text { Report on examination of films made } \\
\text { from swabbing. }\end{array}$ & 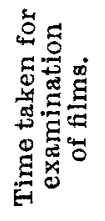 & $\begin{array}{l}\text { Result of cultural } \\
\text { examination. }\end{array}$ & $\begin{array}{l}\text { Time taken for } \\
\text { cultural } \\
\text { examination. }\end{array}$ \\
\hline 1 & $\begin{array}{l}\text { Swabbing from vagina, taken } \\
\text { some days after raginal } \\
\text { hysterectomy for fibrosis } \\
\text { uteri; discharge was at the } \\
\text { time offensive, with an } \\
\text { absorption temperature of } \\
\text { 1010 F.; patient recovered } \\
\text { well, }\end{array}$ & $\begin{array}{l}\text { Films crowded with different varieties of } \\
\text { bacilli, both Gram-positive and Gram- } \\
\text { negative; Gram-positive diplococei (? staphy- } \\
\text { lococi) present; pus cells present. } \\
\text { Conclusions : Staphylococei may be present; } \\
\text { Bacillus coli may be present; pus cells are } \\
\text { present, and therefore the presence of } \\
\text { pyogenic organisms is to be suspected. }\end{array}$ & $\begin{array}{l}15 \\
\text { mins. }\end{array}$ & $\begin{array}{l}\text { Cultivation produced } \\
\text { growths of Bacillus coli } \\
\text { and Staphylococeus } \\
\text { aureus with saprophytic } \\
\text { bacilli. }\end{array}$ & 24 hours. \\
\hline 2 & $\begin{array}{l}\text { Swabbing from endocervix } \\
\text { just before application of } \\
\text { forceps; patient in second } \\
\text { stage for } 20 \text { hours ; frequent } \\
\text { Faginal examinations had } \\
\text { been made. }\end{array}$ & $\begin{array}{l}\text { Films showed a large number of cocci, all } \\
\text { Gram-negative, and a few Gram-negative } \\
\text { bacilli no pus cells. } \\
\text { Conclusions: The cocci are probably non- } \\
\text { pathogenic; their being Gram-negative } \\
\text { shows that they are not staphylococci, } \\
\text { streptococei, or pneumococci ; they might } \\
\text { be gonococci, but the absence of pus cells is } \\
\text { against this; very few bacilli are present, } \\
\text { but these are Gram-negative, and the } \\
\text { presence of Bacillus coli cannot be excluded } \\
\text { with certainty. }\end{array}$ & $\begin{array}{l}15 \\
\text { mins. }\end{array}$ & $\begin{array}{l}\text { No growth of any patbo- } \\
\text { geuic organism was ob- } \\
\text { tained. }\end{array}$ & 24 hours. \\
\hline 3 & $\begin{array}{l}\text { Swabbing from endocervix; } \\
\text { normal labour, with delayed } \\
\text { second stage; some vaginal } \\
\text { examinations made. }\end{array}$ & $\begin{array}{l}\text { Films showed a very small number of bacilli, } \\
\text { all Gram-positive; no pus cells. } \\
\text { Conclusions : Probably no pathogenic organ- } \\
\text { isms present. }\end{array}$ & $\begin{array}{l}10 \\
\text { mins. }\end{array}$ & $\begin{array}{l}\text { No growth of any baeillus } \\
\text { was obtained; two agar } \\
\text { plates were planted, and } \\
\text { the only growth ob- } \\
\text { tained consisted of four } \\
\text { colonies of sarcinæ. }\end{array}$ & 24 hours. \\
\hline 4 & $\begin{array}{l}\text { Swabbing from endocervix; } \\
\text { puerperal septicæmia 12 } \\
\text { months previously; metror- } \\
\text { rbagia last few months; } \\
\text { curettage; much adenoid } \\
\text { tissue removed. }\end{array}$ & $\begin{array}{l}\text { Films showed a few bacilli, mostly too small } \\
\text { to be Bacillus coli, and all Gram-positive; a } \\
\text { few Gram-positive diplococci; pus cells } \\
\text { present (few). } \\
\text { Conclusions : Bacillus coli probably not pre- } \\
\text { sent; the Gram-positive diplococci may be } \\
\text { staphylococci. }\end{array}$ & $\begin{array}{l}16 \\
\text { mins. }\end{array}$ & $\begin{array}{l}\text { Oultivation produced } \\
\text { Gram-positive bacilli ( } 3 \\
\text { varieties, all apparently } \\
\text { saprophytic) and a few } \\
\text { colonies of sarcinæ; no } \\
\text { staphylococci. }\end{array}$ & $\begin{array}{l}\text { Planted on Friday } \\
\text { no visible growth on } \\
\text { Saturday; then no } \\
\text { examined until Mon } \\
\text { day. }\end{array}$ \\
\hline 5 & $\begin{array}{l}\text { Swabbing from external os } \\
\text { before curettage for some- } \\
\text { what offensive leucorrhcea } \\
\text { and metrorrhagia. }\end{array}$ & $\begin{array}{l}\text { Films showed many Gram-staining cocci, } \\
\text { mostly in pairs; one chain of } 4 \text { cocci and } \\
\text { one of } 5 \text { cocci seen; the bacilli are both } \\
\text { Gram-positive and Gram-negative; some } \\
\text { of the diplococci resembled pneumococi in } \\
\text { shape, and a film was therefore stained with } \\
\text { capsule stain, but no capsule was seen. } \\
\text { Conclusions: Bacillas coli may be present; } \\
\text { staphylococci and streptococei may be } \\
\text { present. }\end{array}$ & $\begin{array}{l}17 \\
\text { mins. }\end{array}$ & $\begin{array}{l}\text { Cultivation produced } \\
\text { growths of Bacillus } \\
\text { coli, streptococcus, and a } \\
\text { few colonies of Staphylo- } \\
\text { coccus aureus. }\end{array}$ & 24 hours. \\
\hline
\end{tabular}

NoTE.-Founded on the indications stated in the paper, Nos. 1 and 5 would have been treated br hysterectomy, Nos. 2 and 3 by Maxwell's Irrigation, eventration of the uterus, \&c., and Casarean section, and No. 4 by either craniotomy or hysterectomy, after consultation with thepatient and her husband. 